\title{
Detection of Methyl Salicylate Using Bi-Enzyme Electrochemical Sensor Consisting Salicylate Hydroxylase and Tyrosinase
}

\author{
Yi Fang ${ }^{1}$, Hannah Bullock ${ }^{2}$, Sarah A. Lee ${ }^{3}$, Narendran Sekar ${ }^{1}$, Mark A. \\ Eiteman $^{3}$, William B. Whitman ${ }^{2}$ and Ramaraja P. Ramasamy ${ }^{*}$ \\ ${ }^{1}$ Nano Electrochemistry Laboratory, College of Engineering, University of Georgia, Athens, GA \\ 30602 \\ ${ }^{2}$ Department of Microbiology, University of Georgia, Athens, GA 30602. \\ ${ }^{3}$ College of Engineering, University of Georgia, Athens, GA 30602. \\ * Corresponding Author E-mail: rama@uga.edu
}




\title{
Detection of Methyl Salicylate Using Bi-Enzyme Electrochemical Sensor Consisting Salicylate Hydroxylase and Tyrosinase
}

\author{
Yi Fang ${ }^{1}$, Hannah Bullock ${ }^{2}$, Sarah A. Lee ${ }^{3}$, Narendran Sekar ${ }^{1}$, Mark A. \\ Eiteman $^{3}$, William B. Whitman ${ }^{2}$ and Ramaraja P. Ramasamy ${ }^{1^{*}}$ \\ ${ }^{1}$ Nano Electrochemistry Laboratory, College of Engineering, University of Georgia, Athens, GA
} 30602

${ }^{2}$ Department of Microbiology, University of Georgia, Athens, GA 30602.

${ }^{3}$ College of Engineering, University of Georgia, Athens, GA 30602.

* Corresponding Author E-mail: rama@uga.edu

\begin{abstract}
Volatile organic compounds have been recognized as important marker chemicals to detect plant diseases caused by pathogens. Methyl salicylate has been identified as one of the most important volatile organic compounds released by plants during a biotic stress event such as fungal pathogen infection. Advanced detection of these marker chemicals could help in early identification of plant diseases and has huge significance for agricultural industry. This work describes the development of a novel bi-enzyme based electrochemical biosensor consisting of salicylate hydroxylase and tyrosinase enzymes immobilized on carbon nanotube modified electrodes. The amperometric detection using the bi-enzyme platform was realized through a series of cascade reactions that terminate in an electrochemical reduction reaction. Electrochemical measurements revealed that the sensitivity of the bi-enzyme sensor was $30.6 \pm$ $2.7 \mu \mathrm{A} \cdot \mathrm{cm}^{-2} \cdot \mu \mathrm{M}^{-1}$ respectively and the limit of detection and limit of quantification were $13 \mathrm{nM}$ $(1.80 \mathrm{ppb})$ and $39 \mathrm{nM}(5.39 \mathrm{ppb})$ respectively. Interference studies showed no significant interference from the other common plant volatile compounds. Synthetic analyte studies revealed that the bi-enzyme based biosensor can be used to reliably detect methyl salicylate released by unhealthy plants.
\end{abstract}

Key words: methyl salicylate; biosensor; salicylate hydroxylase; tyrosinase; volatile organic compound. 


\section{Introduction}

The rapid increase in world population has put enormous pressure on food and agriculture industry (Ingram 2011; Keinan and Clark 2012; Smil 2001). Demand for food is projected to double by 2050, which requires that agricultural and food production must be increased to meet that demand (Godfray et al. 2010). Agricultural productivity is directly dependent on minimizing the crop losses and improving overall quality. The economic losses to agriculture due to pathogenic diseases of crops could be attributed to excessive and unnecessary spraying of chemicals (which increases cost), untimely application of fungicides (leads to crop damage) and lack of suitable technology to warn about the onset of pathogenic diseases. All of these can be addressed by a rapid detection technology that is capable of detecting diseases in early stages. Precision agriculture with detailed information about severity and specific location of a pest or pathogen infection can be realized through early detection systems. The commonly available methods for identifying infections in crops are the molecular biology based direct methods (i.e. phytopathogens detection) such as polymerase chain reaction (PCR), immunofluorescence (IF), fluorescence in-situ hybridization (FISH), enzyme-linked immunosorbent assay (ELISA) and flow cytometry (FCM) (Fang and Ramasamy 2015; Sankaran et al. 2010), and indirect methods (i.e. phytodisease symptom detection) such as thermography, fluorescence and hyperspectral imaging (Mahlein et al. 2012). Among the other less explored indirect methods of plant disease detection, volatile profiling of the infected plants have been suggested as a useful strategy to selectively identify the type and severity of crop infections as plants release specific volatile compounds during a biotic stress event such as fungal infections (Fang et al. 2014; Laothawornkitkul et al. 2008). Commonly used techniques for volatile organic compound (VOC) analysis such as gas-chromatography mass-spectrometry (GC-MS) and head-space solid phase microextraction (HS-SPME) confine the usage mostly to the lab and are prohibitively expensive for on-field use (Kessler and Baldwin 2001; Pawliszyn 1999; Schmelz et al. 2003; Zhang and Pawliszyn 1993). On the other hand, electrochemical biosensors have been largely overlooked for this application. Electrochemical biosensors are portable, can provide reliable real-time measurement and possess other attributes such as high accuracy, short response time, high sensitivity and specificity and low limit of detection (LOD) (Bakker 2004). 
Methyl salicylate (MeSA) was discovered as one of the most distinct VOCs released by stressed plants through Shikimate biosynthesis pathway (Kessler and Baldwin 2001; Loake and Grant 2007). For example, MeSA was observed to be released by pepper plants upon infection by a fungal pathogen Phytophthora capsici (Buttery et al. 1969), by tobacco plants during the infection of tobacco mosaic virus (TMV) (Seskar et al. 1998), and by soybean plants during the infection of soybean aphid (Zhu and Park 2005). Unlike other green leaf volatiles (GLVs), MeSA is an allelochemical that can be produced not only at infection site but throughout the plant (stem, root, leaf etc), which makes it easier to detect (Dudareva et al. 2006; Pichersky et al. 2006). Previous studies indicate that detection of methyl salicylate can be achieved either by direct electrochemical reaction of salicylate (the hydrolyzed form of methyl salicylate) (Cascalheira et al. 2004). With the presence of salicylate hydroxylase, consumption of NADH, $\mathrm{O}_{2}$ and generation of $\mathrm{CO}_{2}$ can also be used for salicylate detection (Neto et al. 1999). In addition, in our previous work, we reported the application of a bi-enzyme biosensing platform based on alcohol oxidase and horseradish peroxidase enzymes as recognition molecules for MeSA detection through the detection of methanol, a hydrolysis product of MeSA (Fang et al. 2016). In this work, a more selective enzyme combination for bi-enzyme biosensor based on salicylate hydroxylase and tyrosinase was used to improve the sensitivity and prevent unwanted crossreactions that may result in false positive signals in our previous bi-enzyme system.

Salicylate, a main compound formed after hydrolysis of MeSA, can be electrochemically detected using salicylate hydroxylase (SH) as the recognition element with high selectivity. The enzyme is immobilized through an in-house developed tethering chemistry that binds the enzyme to the multi-walled carbon nanotubes on the surface of glassy-carbon electrodes. The CNT provides high surface area for enhanced sensitivity while at the same time, provides electronic conductivity inside the biosensor platform. $\mathrm{SH}$ is an FAD-dependent monooxygenase that converts salicylate to catechol in the presence of NADH and oxygen (Katagiri et al. 1965; Yamamoto et al. 1965). Although salicylate acts as the natural substrate for SH, other pseudosubstrates such as benzoate derivatives can also be catalyzed by SH. This issue is addressed by employing a second enzyme - tyrosinase (TYR) as a part of the recognition element, in order to build an enzyme cascade that provides highly selective MeSA detection on the electrode. The reaction scheme of the enzyme cascade and the mechanism behind electrochemical detection are illustrated as steps 1 to 4 in Figure 1. Salicylate produced from the hydrolysis of methyl 
salicylate (step 1 in Figure 1) reacts with SH and generate catechol as the intermediate (step 2) (Yamamoto et al. 1965). Catechol can be further oxidized enzymatically by TYR to produce 1,2benzoquinone (step 3) (Rassaei et al. 2012). The biochemically generated 1,2-benzoquinone can then be electrochemically reduced to catechol by the electrode thereby regenerating catechol (step 4) (Enache and Oliveira-Brett 2011). Therefore, the amperometric detection of salicylate can be realized through measuring the reduction current of 1,2-benzoquinone. Since the MeSA detection is realized through salicylate (see Figure 1) and that the methanol formed during hydrolysis of MeSA does not impact the MeSA detection (as found in our previous work) (Fang et al. 2016), the hydrolyzed form of MeSA, i.e. salicylate was used in this work as the analyte for fundamental studies.

\section{Materials and Methods}

\subsection{Materials}

Tyrosinase (E.C. 1.14.18.1) derived from mushroom (lyophilized powder, $\geq 1000 \mathrm{unit} / \mathrm{mg}$ solid), methyl salicylate and farnescene were purchased from Sigma-Aldrich and used as received. Humulene and trimethylbenzene were obtained from Aldrich for the experiments. Multiwalled carbon nanotubes (MWCNTs) were obtained from DropSens Inc. 1-pyrenebutanoic acid succinimidyl ester (PBSE) was purchased from AnaSpec Inc. (Fremont CA). Dimethylformamide (DMF), salicylate and NADH were purchased from Acros Organics. FAD and dichlorobenzene were purchased from Alfa Aesar and Eastman respectively. Methanol and phosphoric acid were obtained from Fisher Scientific. All reagents used in this project were analytical grade. 0.1 M phosphate buffer (PB) ( $\mathrm{pH}$ 7.6) was used as the electrolyte for all experiments. All the aqueous solutions were prepared using 18.2 M $\Omega$ nano pure de-ionized (DI) water. Solutions were oxygenated by purging with purified oxygen for $15 \mathrm{~min}$ before each experiment.

\subsection{Recombinant synthesis of salicylate hydroxylase}

Salicylate hydroxylase enzyme is not commercially available and therefore was synthesized recombinantly in this work. Gene $n a h G$ that codes salicylate hydroxylase in Pseudomonas putida can be found from previous publications (You et al. 1991). The nahG gene was codon optimized for expression in E.coli and synthesized by GenScript with histidine tag $(6 \mathrm{X})$ at $\mathrm{N}$ - terminal of the sequence. The recombinant plasmid pTrc99A-nahG was constructed 
by cloning the $n a h G$ gene into pTrc99A that harbors ampicillin resistance gene $\left(\mathrm{amp}^{\mathrm{R}}\right)$ as an antibiotic selection marker (Figure S1). The expression of $n a h G$ gene was under the control of $\mathrm{P}_{\text {lac }}$ and was inducible by addition of isopropyl $\beta$-D-1-thiogalactopyranoside (IPTG). Recombinant plasmid was transformed to E. coli XL1-blue through electroporation for the purpose of enzyme expression. The resultant transformants of E. coli XL1-blue was cultured in test tubes, where each contains $3 \mathrm{~mL}$ of LB media (with $100 \mu \mathrm{g} / \mathrm{mL}$ of ampicillin). The strain was cultured overnight aerobically at $37^{\circ} \mathrm{C}$. Each of the overnight culture was further inoculated into $250 \mathrm{~mL}$ fresh LB media (with $100 \mu \mathrm{g} / \mathrm{mL}$ of ampicillin) and left to grow at $37{ }^{\circ} \mathrm{C}$ until $\mathrm{OD}_{600}$ reached 0.6. $1 \mathrm{mM}$ of IPTG was added to initiate the expression of salicylate hydroxylase at $20^{\circ} \mathrm{C}$ for 8 hours. Figure S1 shows the schematic summarizing of the procedures involved in cloning and expression of $n a h G$ in E. coli. Cell pellets were collected by centrifugation. Then cell pellets were rinsed with $20 \mathrm{mM} \mathrm{PB} \mathrm{pH} 7.6$ twice to remove the LB media before being lysed through French Press. The supernatant was collected as crude extract by centrifugation. The crude extract was purified through fast-protein liquid chromatography with HisTrap ${ }^{\mathrm{TM}}$ HP column. Different segments of eluent were tested by a traditional enzyme assay with addition of FAD and cofactor (White-Stevens and Kamin 1972; Yamamoto et al. 1965). The segment with highest enzyme activity was added with glycerol to final concentration of $20 \%$ (You et al. 1990). The enzyme stock was frozen and stored at $-80{ }^{\circ} \mathrm{C}$ for all the experiments.

\subsection{Apparatus}

Cyclic voltammetry (CV) and constant potential amperometry (CPA) were performed using CHI 920c model potentiostat. Three-electrode system consisting of a $3 \mathrm{M} \mathrm{Ag} / \mathrm{AgCl}$ reference electrode, a platinum wire counter electrode, and a glassy carbon (GC) working electrode purchased from Pine Instrument Company were used for electrochemical measurements in a conventional glass voltammetry cell. All experiments were conducted at $22 \pm$ $2^{\circ} \mathrm{C}$.

\subsection{Electrode preparation and electrochemical measurement}

GC was first polished on polishing pad with 0.05 micron alumina polishing powder before each experiment. The electrode was cleaned in the ultrasonic cleaner for 5 minutes to remove the polishing powder adhered to the surface of the electrode. The electrode was rinsed with DI water before surface modification with carbon nanotubes (CNT). CNT suspension was prepared by ultrasonicating $1 \mathrm{mg}$ of multiwalled CNT in $1 \mathrm{~mL} \mathrm{DMF}$ for an hour. The electrode 
was modified with CNT by drop casting $16 \mu \mathrm{L}$ (in 8 steps of $2 \mu \mathrm{L}$ ) followed by drying at $75^{\circ} \mathrm{C}$. The electrode was allowed to cool down on the ice before $2 \mu \mathrm{L}$ of $10 \mathrm{mM}$ PBSE in DMF were added. The electrode was incubated on ice for 15 minutes to allow the non-covalent binding between PBSE and CNT. DMF and 0.1 M PB pH 7.6 were then used sequentially to remove the excessive PBSE from the modified electrode surface. A solution of TYR was prepared by dissolving $5 \mathrm{mg}$ TYR in $1 \mathrm{~mL} 20 \mathrm{mM}$ PB pH 6.6 and a bi-enzyme solution mixture was prepared by mixing $5 \mu \mathrm{L}$ of salicylate hydroxylase solution and $5 \mu \mathrm{L}$ TYR solution. Bi-enzyme immobilized sensor was fabricated by drop casting $10 \mu \mathrm{L}$ of bi-enzyme solution on the electrode surface, and the electrode was incubated on ice for 30 minutes to allow covalent bind of PBSE and both enzymes. CV was performed after each step of electrode modification and the capacitance displayed was used to illustrate the modification procedure. For control studies, mono-enzyme modified electrodes were also fabricated with only one of the two enzymes, namely SH. The mono-enzyme electrode was prepared by drop casting $5 \mu \mathrm{L}$ of salicylate hydroxylase solution. Electrode was rinsed with 0.1 M PB pH 7.6 to remove any unimmobilized enzyme before measurement. For CV measurements, the potential was scanned from $0.4 \mathrm{~V}$ to $0.2 \mathrm{~V}$ for bi-enzyme immobilized electrode and from $-0.2 \mathrm{~V}$ to $0.4 \mathrm{~V}$ for both the unimmobilized and mono-enzyme modified electrodes. Scan rate of $20 \mathrm{mV} \mathrm{s}^{-1}$ and sample interval of $0.001 \mathrm{~V}$ was applied for all $\mathrm{CV}$ experiments. The initial potential for constant potential amperometry (CPA) with GC electrode was set to $0.025 \mathrm{~V}$ with $0.1 \mathrm{~s}$ interval for data collection.

\section{Results and Discussions}

\subsection{Expression and purification of salicylate hydroxylase}

Crude extract of SH enzyme synthesized from E. coli XL1-blue cells was collected from the French Press after homogenization and centrifugation. The crude extract was first evaluated by traditional SH enzyme assay with addition of FAD as cofactor (White-Stevens and Kamin 1972; Yamamoto et al. 1965). $4 \mathrm{~mL}$ of crude extract was obtained and the protein concentration of SH in the crude extract was determined by Bradford assay to be $\sim 35 \mathrm{mg}$ of total protein in 4 $\mathrm{mL}$ (Kruger 1994, 2009). Catalytic assay revealed that the total and specific activity of SH were $\sim 23 \mathrm{U}$ and $0.67 \mathrm{U} / \mathrm{mg}$ of protein. After purification by fast protein liquid chromatography (FPLC) with HisTrap ${ }^{\mathrm{TM}} \mathrm{HP}$ column, $0.73 \mathrm{mg}$ of protein with the total activity of 8.96 units was obtained. 
Although the purification yield was only $39 \%$, the specific activity of SH increased approximately 19 fold to $\sim 12.3 \mathrm{U} / \mathrm{mg}$ (Table 1 ).

\subsection{Cyclic voltammetry on bi-enzyme modified electrode}

The step-by-step electrode modification (modification of CNT, PBSE and bi-enzyme) can be demonstrated by the increasing capacitance change from $\mathrm{CV}$ during the modification (Figure S2). Control CV experiments were performed first using the mono-enzyme biosensor made of SH immobilized CNT electrodes. The study was carried out by sequentially adding FAD, NADH and salicylate followed by $\mathrm{CV}$ measurement after each addition. $100 \mu \mathrm{L}$ of 0.1 $\mathrm{mM}$ FAD was first added due to the requirement of FAD as the cofactor for the SH enzyme reaction. The results of this $\mathrm{CV}$ experiment as shown in Figure 2A demonstrated that FAD does not show any electrochemical activity within the range of $-0.2 \mathrm{~V}$ to $0.4 \mathrm{~V}$ and confirmed that any peak appeared in the subsequent experiments were not that of FAD redox reactions. Then $50 \mu \mathrm{L}$ of $10 \mathrm{mM} \mathrm{NADH}$ was added as the second cofactor and the electrochemical redox activity of NADH was observed using CV between the same voltage window. The objective of this step is to eliminate any background currents from NADH in the measurements. As shown in Figure 2A, a small oxidation peak can be found around $0.2 \mathrm{~V}$ due to the direct electrochemical oxidation of $\mathrm{NADH}$ to $\mathrm{NAD}^{+}$. This corresponds with earlier reports of direct electrochemistry of NADH $(\mathrm{Li}$ et al. 2012a; Li et al. 2012b). In the next step, (sodium) salicylate was added to the electrolyte to a final concentration of $25 \mu \mathrm{M}$ and another CV scan was performed. Under aerobic conditions, salicylate would be biocatalytically reduced by SH to catechol while simultaneously NADH to $\mathrm{NAD}^{+}$(steps 1 and 2 in Figure 1) as per the reaction below:

$$
\text { Salicylate }+\mathrm{NADH}+2 \mathrm{H}^{+}+\mathrm{O}_{2} \stackrel{\text { Salicylate hydroxylase }}{\longrightarrow} \text { Catechol }+\mathrm{NAD}^{+}+\mathrm{H}_{2} \mathrm{O}+\mathrm{CO}_{2}
$$

The resulting $\mathrm{CV}$ response is shown in Figure 2A, where an oxidation peak at $0.15 \mathrm{~V}$ was observed upon the addition of $25 \mu \mathrm{M}$ salicylate (Figure 2A). This peak can be attributed to the combined electrochemical oxidation of $\mathrm{NADH}$ and catechol on the electrode surface. Catechol is electrochemically oxidized to 1,2-benzoquinone as per the following reaction at $0.15 \mathrm{~V}$ (Enache and Oliveira-Brett 2011; Umasankar and Ramasamy 2013b, 2014):

$$
\text { Catechol } \rightarrow 1,2 \text { - Benzoquinone }+2 e^{-}+2 \mathrm{H}^{+}
$$

The reduction wave in all voltammograms below $-0.1 \mathrm{~V}$ correspond to the reduction of dissolved oxygen present in the system. After understanding the control response of $\mathrm{SH}$ immobilized mono-enzyme CNT electrode, similar set of experiments was performed using the bi-enzyme 
modified CNT electrode that contain both SH and TYR as recognition molecules. The study was carried out by sequential addition of FAD, NADH and salicylate followed by CV measurement after each addition. Similar to the control electrode (mono-enzyme sensor), no significant oxidation/reduction peak can be observed after adding FAD (Figure 2B). The mild hump noticed at $0.2 \mathrm{~V}$ in all the voltammograms in Figure $2 \mathrm{~B}$ is a characteristic of the blue copper proteins such as tyrosinase as found in our earlier work (Ramasamy et al. 2010; Umasankar and Ramasamy 2013a, b). However, unlike the SH mono-enzyme sensor, addition of NADH did not result in an oxidation peak in the case of bi-enzyme sensor (SH and TYR). This could likely be due to the reduced transport of $\mathrm{NADH}$ from the bulk to the electrode surface due to the presence of additional protein in the CNT matrix on the modified electrode. With addition of $25 \mu \mathrm{M}$ salicylate, a prominent reduction peak appeared below $0.025 \mathrm{~V}$ as shown in Figure $2 \mathrm{~B}$. This distinct reduction peak appears only when both SH and TYR are present in the system and thus can be attributed to the direct electrochemical reduction of 1,2-benzoquinone. 1,2-benzoquinone was produced by the biocatalytic oxidation of catechol by tyrosinase as per the following reaction:

$$
2 \text { Catechol }+\mathrm{O}_{2} \stackrel{\text { tyrosinase }}{\longrightarrow} 21,2 \text { - benzoquinone }+2 \mathrm{H}_{2} \mathrm{O}
$$

Unlike the mono-enzyme SH electrode, the bienzyme electrode did not exhibit a direct electrochemical oxidation of the catechol in the $0.015 \mathrm{~V}$ region of the anodic wave. This suggests that the biocatalytic oxidation reaction of catechol by TYR proceeds at a high rate depleting its surface concentration rather rapidly.

A further set of control experiments were performed on both unimmobilized and TYRimmobilized mono-enzyme electrodes, both in the presence and absence of catechol. The results of this experiment are shown in Figure S3A, which clearly establishes the catechol redox peaks at $\sim 0.15 \mathrm{~V}$ in the absence of TYR on the modified electrode (red curve in Figure S3A). Another set of control experiments were performed on both unmodified and TYR modified mono-enzyme electrodes, both in the presence and absence of salicylate, the result of which are shown in Figure S3B. None of the voltammograms shown in Figure S3B showed a direct electrochemical reduction of 1,2-benzoquinone as observed in the Figure S3B (blue curve). This indicates that the 1,2-benzoquinone could only be generated in the system through the cascade reactions (steps 1 to 4), when both SH and TYR are present. The results provide conclusive evidence that the bi- 
enzyme sensor made of SH and TYR enzymes immobilized on CNT matrix provide a reliable and selective detection of salicylate at potentials below $0.15 \mathrm{~V}$.

\subsection{Determining optimal ratio of SH and TYR on electrode surface}

The loading of either enzymes (SH or TYR) as well as the ratio of their loadings on the CNT electrode surface would have a significant influence on the electrochemical detection and the resulting sensor performance. The difference in catalytic constants $\left(\mathrm{K}_{M}\right.$ and $\left.\mathrm{k}_{\mathrm{cat}}\right)$ between the two enzymes and the difference in mass transport coefficients of the reactants and products must be optimized in order for the cascade reactions (steps 1 to 4 in Figure 1) to proceed. For example, if SH loading on the electrode is insufficient, the cascadic reactions would be limited by catechol generation reaction, leading to low 1,2-benzoquinone generation and hence low currents on the electrode, thereby directly impacting the sensitivity of salicylate detection. On the other hand, the cascade reactions will also be limited by step 3 (catechol to 1,2-benzoquinone conversion), if TYR loading is insufficient, which can also impact the selectivity of detection. Therefore it is essential to optimize the kinetics and transport inside the enzyme-CNT matrix of the bi-enzyme sensor to ensure optimal conditions for reliable detection of salicylate. However such a precise optimization and control could only be achieved by theoretical treatment of the sensor surface, which is beyond the scope of this work. Therefore a much simpler experimental design approach for fabricating bi-enzyme sensor with different loadings of the two enzymes was attempted in this work. For this purpose, five different volume ratio of SH and TYR enzymes were used for the immobilization on CNT electrode. The loading of SH and TYR used were: $1 \mu \mathrm{L}$ and $9 \mu \mathrm{L}, 3$ $\mu \mathrm{L}$ and $7 \mu \mathrm{L}, 5 \mu \mathrm{L}$ and $5 \mu \mathrm{L}, 7 \mu \mathrm{L}$ and $3 \mu \mathrm{L}$, and $9 \mu \mathrm{L}$ and $1 \mu \mathrm{L}$ respectively on the electrode surface. CV was performed on the five bi-enzyme electrodes in the presence of the same concentration of salicylate, NADH, FAD and oxygen at the experimental $\mathrm{pH} 7.6$ and the results are shown in Figure S4. The results show that rate of 1,2-benzoquinone reduction (as determined by the slope of the reduction wave below $0.15 \mathrm{~V}$ ) differed significantly when the enzyme loading ratio was changed. The inset graph in Figure S4, shows the current density observed at $0.1 \mathrm{~V}$ as a function of $\%$ volume of SH enzyme in the mixture, i.e. $50 \%$ refers to 1:1 volume loading of SH:TYR used for immobilization. The $0.1 \mathrm{~V}$ was outside both kinetic and mass transport limited regions and therefore is an ideal reference point to measure the electrochemical rate. It can also be noted from the insert graph in Figure S4, that the current for a 1:9 SH:TYR ratio was higher than that of 9:1 SH:TYR ratio. The trend indicates that the cascade reactions are limited by the 
reaction catalyzed by TYR (step 3) rather than the reaction catalyzed by SH (step 2). The highest sensitivity (current density) was observed for a SH:TYR volume ratio of 1:1. This corresponds to $1.83 \mu \mathrm{g}$ of SH and $25 \mu \mathrm{g}$ of TYR on the electrode. Consequently, the mixture of $5 \mu \mathrm{L} \mathrm{SH}$ and 5 $\mu \mathrm{L}$ TYR was used in all the remaining experiments to investigate the sensor performance characteristics such as sensitivity and limit of detection.

\subsection{Electrochemical response of the bi-enzyme biosensor}

Transient performance of the sensor was measured using the CV to determine parameters such as sensitivity, LOD, limit of quantification (LOQ) and reliable linear range for salicylate detection. Since no electrochemical peak can be observed by adding FAD and NADH (recall Figure $2 \mathrm{~B}$, baseline was collected by $\mathrm{CV}$ after adding $100 \mu \mathrm{L}$ of $0.1 \mathrm{mM}$ FAD and $50 \mu \mathrm{L}$ of 10 $\mathrm{mM}$ NADH. Then salicylate solution was added in steps to different final concentrations $2.3 \mu \mathrm{M}$, $4.6 \mu \mathrm{M}, 9.3 \mu \mathrm{M}, 18.6 \mu \mathrm{M}, 27.8 \mu \mathrm{M}$ and $46.3 \mu \mathrm{M}$ and after each addition a $\mathrm{CV}$ was performed. The resulting voltammograms shown in Figure 3A indicated that the 1,2-benzoquinone reduction increased progressively (below $0.15 \mathrm{~V}$ ) as the salicylate concentration in the electrolyte was increased. The reduction currents increased up to $46.3 \mu \mathrm{M}$ of salicylate beyond which the enzymes exhibited substrate saturation. The effect of substrate limitation on the enzyme kinetics can be explained by the Michaelis-Menten equation below:

$$
V=V_{\max }[S] /\left(K_{m}+[S]\right)
$$

As the concentration of substrate $[\mathrm{S}]$ is increased, the enzymatic reaction rate will eventually reach saturation and be equal to $\mathrm{V}_{\max }$. The biosensor parameters were calculated from the $\mathrm{CV}$ data at $0.025 \mathrm{~V}$ as reference point. The insert graph in Figure 3B shows the current density at $0.025 \mathrm{~V}$ at different concentrations within the linear range of detection. The values were average of 3 replicates. From the data, the sensitivity was calculated to be $21.3 \pm 1.9 \mu \mathrm{A} \cdot \mathrm{cm}^{-2} \cdot \mu \mathrm{M}^{-1}$ and the LOD and LOQ were determined to be $0.14 \pm 0.02 \mu \mathrm{M}$ and $0.42 \pm 0.04 \mu \mathrm{M}$ respectively. The linear range of salicylate detection using $\mathrm{CV}$ is 0 to $27.8 \mu \mathrm{M}\left(\mathrm{R}^{2}=0.99\right)$ as listed in Table S1.

Since $\mathrm{CV}$ is a transient technique, it is usually used to obtain a firsthand understanding of the sensor but is generally not used as measurement tool in real biosensors. A more reliable steady state measurement can be obtained by constant potential amperometry (CPA). For the CPA, the initial potential was set at $0.025 \mathrm{~V}$ and biosensor was stabilized for 2 minutes before adding $100 \mu \mathrm{L}$ of $0.1 \mathrm{mM} \mathrm{FAD}$ and $50 \mu \mathrm{L}$ of $10 \mathrm{mM} \mathrm{NADH}$ at 1 minute intervals sequentially. After a 1 minute of preconditioning, salicylate was introduced stepwise in different quantities to 
final concentration of $2.3 \mu \mathrm{M}, 4.6 \mu \mathrm{M}, 9.3 \mu \mathrm{M}, 18.6 \mu \mathrm{M}, 27.8 \mu \mathrm{M}$ to $46.3 \mu \mathrm{M}$. The reduction current was continuously monitored for 1 minute at each concentration until the next step addition of salicylate. For each addition of salicylate, the reduction current reached steady value within short time and at high concentrations began to fade due to the mass transfer limitations (Figure 3B). Therefore, the highest current measured at each concentration was used for calculating the sensor parameters, which are also reported in Table S1. Compared to the CV, the bi-enzyme biosensor exhibited higher sensitivity $\left(30.6 \pm 2.7 \mu \mathrm{A} \cdot \mathrm{cm}^{-2} \cdot \mu \mathrm{M}^{-1}\right)$, lower LOD $(0.013$ $\pm 0.005 \mu \mathrm{M})$ and lower LOQ $(0.039 \pm 0.015 \mu \mathrm{M})$ in the CPA measurements with the same linear range of salicylate detection 0 to $27.8 \mu \mathrm{M}\left(\mathrm{R}^{2}=0.99\right)$ (Table S1). Compared to the previously developed bi-enzyme methyl salicylate biosensor consisting of alcohol oxidase and peroxidase, we successfully increased the sensitivity from $0.282 \mu \mathrm{A} \cdot \mathrm{cm}^{-2} \cdot \mu \mathrm{M}^{-1}$ to $30.6 \mu \mathrm{A} \cdot \mathrm{cm}^{-2} \cdot \mu \mathrm{M}^{-1}$ and lowered the limit of detection from $0.98 \mu \mathrm{M}$ to $13 \mathrm{nM}$ (Fang et al. 2016). The above parameters allows us to realize the quantification of MeSA produced by diseased plants in less than 3 minutes given that the produced MeSA is captured in $2 \mathrm{~mL}$ electrochemical cell for detection based on the MeSA production rate of $283 \mathrm{ng} / \mathrm{plant} / \mathrm{hr}$ (Shulaev et al. 1997).

\subsection{Evaluation of reusability of the bi-enzyme biosensor}

Enzyme based biosensors are not meant for extended period of storage or repeated use as the enzymes in the biorecognition element deteriorate over time. However the biosensor must be able to perform repeatedly during multiple measurements within a short period, to justify its adoption to a commercial product over other competitive technologies. To this end, reusability of the bi-enzyme biosensor was evaluated for 10 repetitions of salicylate detection and the results are shown in Figure 4A. Similar to the sensitivity determination, salicylate solution was gradually added to the electrolyte in the presence of FAD and NADH. The experiment was repeated 10 times and after each repetition, the electrode was taken out and rinsed to remove any residual catechol or 1,2-benzoquinone present on the surface. Four salicylate concentrations within the linear range namely $4.6,9.3,18.5$ and $27.8 \mu \mathrm{M}$ were analyzed (10 repeatability tests for each concentration, totaling 40 tests).

For low salicylate concentrations of 4.6 and $9.3 \mu \mathrm{M}$, the current kept increasing during the first few repetitions (insert graph in Figure 4A). This could be caused by the residues of 1.2benzoquinone left on the surface of the electrode from the previous repetition that was not removed completely during rinsing. For low salicylate concentrations of 4.6 and $9.3 \mu \mathrm{M}$, the 
current density remained constant at around $100 \%$ of its original value, throughout the 10 repetitions with no obvious loss in sensitivity. On the other hand, at high salicylate concentrations of 18.6 and $27.8 \mu \mathrm{M}$, a continuous loss in sensitivity was observed during the 10 repetitions, suggested that the bi-enzyme sensor in its current form could not be used to reliably detect high concentrations of salicylate beyond $10 \mu \mathrm{M}$ without suitable calibration. While the reason for the sensitivity loss during repeatable measurements at high salicylate concentration could be attributed the imbalance in the kinetics and mass transport at the sensor-electrolyte interface, investigation of the underlying effects is beyond the scope of this work and could be an attractive goal for future work. It is also important to note that detecting salicylate concentrations above $10 \mu \mathrm{M}$ are generally not necessary for early determination of plant infections as the typical release rate of methyl salicylate by plants would fall below $10 \mu \mathrm{M}$ (equivalent of $1.52 \mathrm{ppm}$ ).

\subsection{Stability of the bi-enzyme biosensor}

In addition to reusability, stability of the biosensor was also evaluated using CPA technique. The bi-enzyme biosensor was fabricated on Day 1 and used to measure different concentrations of salicylate $(4.6,9.3,18.6$ and $27.8 \mu \mathrm{M})$ on Day 1, using the previously described experimental procedure. After the experiments on Day 1, the biosensor was rinsed by $0.1 \mathrm{M}$ phosphate buffer ( $\mathrm{pH} 7.6)$ and stored in $0.1 \mathrm{M}$ phosphate buffer ( $\mathrm{pH} \mathrm{7.6)}$ with $10 \%$ glycerol at $4{ }^{\circ} \mathrm{C}$. The same sets of experiments were repeated on Day 2, 4, 6 and 8 and the current densities for salicylate detection were monitored over time. The results of these measurements are given in Figure 4B. Similar to the results obtained during reusability evaluation, the currents

at low salicylate concentrations $(4.6$ and $9.3 \mu \mathrm{M})$ increased during the $2^{\text {nd }}$ measurement (on Day 2), likely due the residual catechol or 1,2-benzoquinone present on the electrode that could not be removed during rinsing. The current densities for all other salicylate concentrations decreased gradually after Day 2 due to the deterioration of enzymes on the sensor surface (Figure 4B). The currents took longer (10 to 60 second) to reach steady values unlike on Day 1, where it reached steady values within 2 seconds. The results suggest that the biosensor could not be stored for long-term and a suitable stabilization method must be developed before it can be employed for a practical application. While this could be a goal of the future project, the results also indicate that the bi-enzyme sensor provides superior detection capabilities on the first day.

\subsection{Effect of interference on the bi-enzyme biosensor}


In addition to methyl salicylate, other volatile organic compounds (VOCs) can also be released by both healthy and stressed plants. For example, dichlorobenzene (DCB) and 1,2,3trimethylbenzene (TMB) are among the two most expressed VOCs released by healthy uninfected soybean (Zhu and Park 2005). Farnesene (FAR) and humulene (HUM) are also reported to be released by soybean aphid infected soybean plant in addition to methyl salicylate (Zhu and Park 2005). Therefore, the interference caused by FAR, HUM, DCB and TMB on amperometric detection of methyl salicylate using bi-enzyme sensor were evaluated. Since the quantitative detection of methyl salicylate was realized through salicylate measurements, samples have to be hydrolyzed beforehand. Therefore, one potential interfering compound that is produce during this hydrolysis namely methanol $(\mathrm{MeOH})$ was also evaluated. In order to maintain the same ionic strength with 0.1 M PB (pH 7.6), 0.19 M KOH was used to hydrolyze the above-mentioned interfering VOCs for $2 \mathrm{hrs}$ in $90^{\circ} \mathrm{C}$ water bath. Interfering VOC samples were prepared by adding phosphoric acid to adjust the $\mathrm{pH}$ to 7.6 before use. CPA was used for interference evaluation in the presence of $100 \mu \mathrm{L}$ of $0.1 \mathrm{mM}$ FAD and $50 \mu \mathrm{L}$ of $10 \mathrm{mM} \mathrm{NADH}$. Very high concentrations (ranging from $9.3 \mu \mathrm{M}$ to $1.9 \mathrm{mM}$ ) of $\mathrm{MeOH}, \mathrm{FAR}, \mathrm{HUM}$, DCB and TMB were used for the interference study. The upper range of $1.9 \mathrm{mM}$ is 1000 fold higher than the typical VOCs concentration released by pathogen-infected plants. This was done to ensure conservative estimate of interference under extreme (unfavorable) conditions. The experimental procedure used for interference evaluation was similar to that of earlier CPA measurements. The results of these measurements are shown in Figure 5A. The results indicate that MeOH, HUM, DCB and TMB did not contribute interfere significantly with the salicylate detection current at the operating potential of $0.025 \mathrm{~V}$. Although FAR exhibits a noticeable interference (sensitivity of $0.042 \mu \mathrm{A} \cdot \mathrm{cm}^{-2} \cdot \mu \mathrm{M}^{-1}$ ), the currents are negligible compared to that of the control electrode without interfering compounds (sensitivity of $30.61 \mu \mathrm{A} \cdot \mathrm{cm}^{-2} \cdot \mu \mathrm{M}^{-1}$ ) as shown in the insert graph in Figure 5A. It can be concluded that none of the most common interfering compounds identified above cause significant interference to the bi-enzyme sensor towards the detection of salicylate of methyl salicylate.

\subsection{Evaluation of bi-enzyme biosensor using synthetic analyte}

Previous reports provide detailed information about plant volatile signature including the composition and relative molarity of the compounds that are released by uninfected and aphidinfected soybean plants (Zhu and Park 2005). Based on this information, cocktails of VOCs 
simulating the healthy plant and infected soybean plant volatile signatures were prepared and used as synthetic analyte to evaluate the performance of the bi-enzyme sensor at near-practical conditions. The compositions of these synthetic analytes are given in Table S2. The synthetic analytes were prepared in $0.19 \mathrm{M} \mathrm{KOH}$ solution and hydrolyzed at $90{ }^{\circ} \mathrm{C}$ in a water bath for $2 \mathrm{hrs}$. Phosphoric acid was added to adjust $\mathrm{pH}$ to 7.6, before the synthetic analyte samples were used for biosensor tests using CPA measurements. For the CPA measurement, the $\mathrm{pH}$ adjusted synthetic analyte sample was gradually added to the electrolyte containing $100 \mu \mathrm{L}$ of $0.1 \mathrm{mM}$ $\mathrm{FAD}$ and $50 \mu \mathrm{L}$ of $10 \mathrm{mM} \mathrm{NADH}$. The results of this measurement shown in Figure 5B indicate the uninfected synthetic analyte did not exhibit any noticeable reduction current even at high concentrations of the synthetic analyte. On the other hand, for the infected synthetic analyte, a stepwise increase in reduction currents with concentration was observed. The qualitative and quantitative trend of aphid-infected analyte was nearly identical to that of the response from pure salicylate as the analyte (control in Figure 5B). The measured concentration of MeSA in the synthetic analyte was calculated based on the current versus concentration data given in Figure 3B and the results are tabulated in Table S3. The ratio of the measured concentration to the original concentration added was used to determine the recovery. As shown in Table S3, most concentrations within the linear range exhibit satisfactory recovery (close to $100 \%$ ), suggesting reasonable sensor accuracy for real sample measurement and quantification. The bi-enzyme biosensor exhibited a sensitivity of $33.49 \mu \mathrm{A} \cdot \mathrm{cm}^{-2} \cdot \mu \mathrm{M}^{-1}$ for the infected analyte, which was not significantly different from that of the sensitivity obtained for pure methyl salicylate $30.61 \pm$ $2.68 \mu \mathrm{A} \cdot \mathrm{cm}^{-2} \cdot \mu \mathrm{M}^{-1}$ as analyte $(\mathrm{RSD}=8.8 \%)$. The minor sensitivity difference between the simulated infected sample and the upper limit of pure salicylate can be explained by the crossreaction resulting from the interference compounds. This strongly suggests that the bi-enzyme biosensor can be used for reliable detection of real analyte released by infected crops as discussed in the introduction.

\section{Conclusion}

A bi-enzyme based electrochemical biosensing platform consisting of salicylate hydroxylase and tyrosinase as recognition elements immobilized onto a CNT matrix on the screen-printed carbon electrode surface was constructed in this work. The detection is based on a cascade of 4 reaction steps that culminate in the electrochemical reduction of 1,2-benzoquinone 
on the electrode. The fabricated biosensor was evaluated for the selective detection salicylate, a derivative compound of methyl salicylate present in the volatile signature of infected crops. The bi-enzyme biosensor displayed high sensitivity and nano molar range for limit of detection. The sensor exhibited reasonable reusability and stability. The detection suffered very little interference from other common volatile organic compounds released by both uninfected healthy plant and soybean-aphid infected plants. Synthetic analyte studies confirmed that the sensor can be used for reliable detection of real analytes of crop infection with high selectivity. The future work in the development of the sensor would focus on the following: evaluation of the kinetics of the two enzymes and the mass transfer of the reacting specie within the CNT matrix and their impact on the sensor performance, developing a suitable enzyme stabilization method to enhance durability (shelf life) of the sensor, evaluation of the optimal ratio of the two enzymes used in the recognition element.

\section{Acknowledgements}

We acknowledge the National Science Foundation (CBET-1159540) and ACS Herman Frasch Foundation (Grant \# 045097-01) for financial support.

\section{Author Information}

* Corresponding Author: rama@uga.edu 


\section{Tables}

Table 1: Purification data of salicylate hydroxylase from E. coli XL1-blue

\begin{tabular}{ccccccc}
\hline \multicolumn{1}{c}{ Step } & $\begin{array}{c}\text { Vol } \\
(\mathrm{mL})\end{array}$ & $\begin{array}{c}\text { Total } \\
\text { protein } \\
(\mathrm{mg})\end{array}$ & $\begin{array}{c}\text { Total } \\
\text { activity } \\
\text { (units) }\end{array}$ & $\begin{array}{c}\text { Specific } \\
\text { activity } \\
\text { (units/mg) }\end{array}$ & $\begin{array}{c}\text { Purification } \\
\text { (fold) }\end{array}$ & Yield (\%) \\
\hline Crude extract & 4 & 34.8 & 23.3 & 0.67 & $(1)$ & $(100)$ \\
HisTrap $^{\text {TM }} \mathrm{HP}$ & 2 & 0.73 & 8.96 & 12.34 & 19 & 39 \\
\hline
\end{tabular}




\section{Figures}

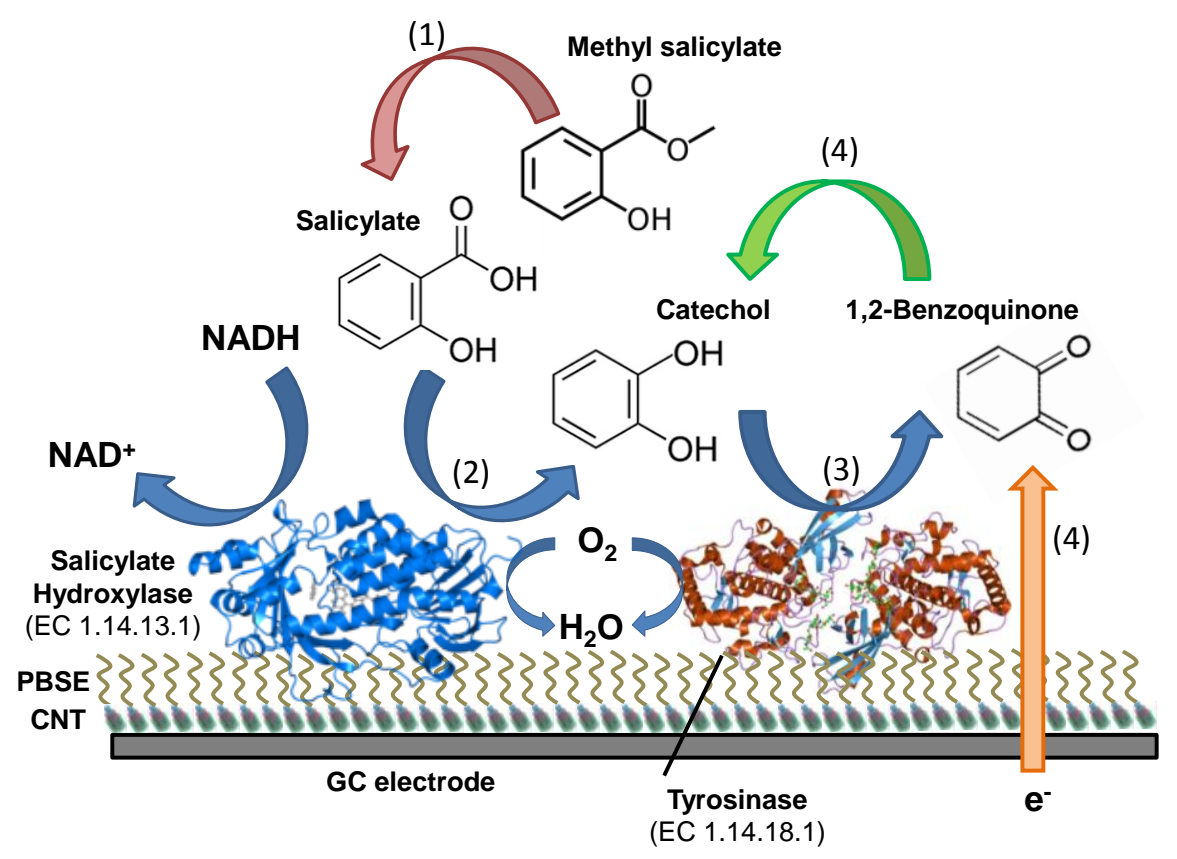

Figure 1: Schematic illustration of methyl salicylate detection on bi-enzyme (salicylate hydroxylase and tyrosinase) based carbon nanotube and PBSE modified biosensor. Methyl salicylate was hydrolyzed manually to generate salicylate and methanol (1). Salicylate, the main analyte was catalyzed by salicylate hydroxylase to generate catechol in presence of NADH and oxygen (2). Catechol is oxidized by tyrosinase to form 1,2-benzoquinone (3). The detection of methyl salicylate is finally realized by measuring the reduction of 1,2-benzoquinone to catechol on the electrode surface (4). 

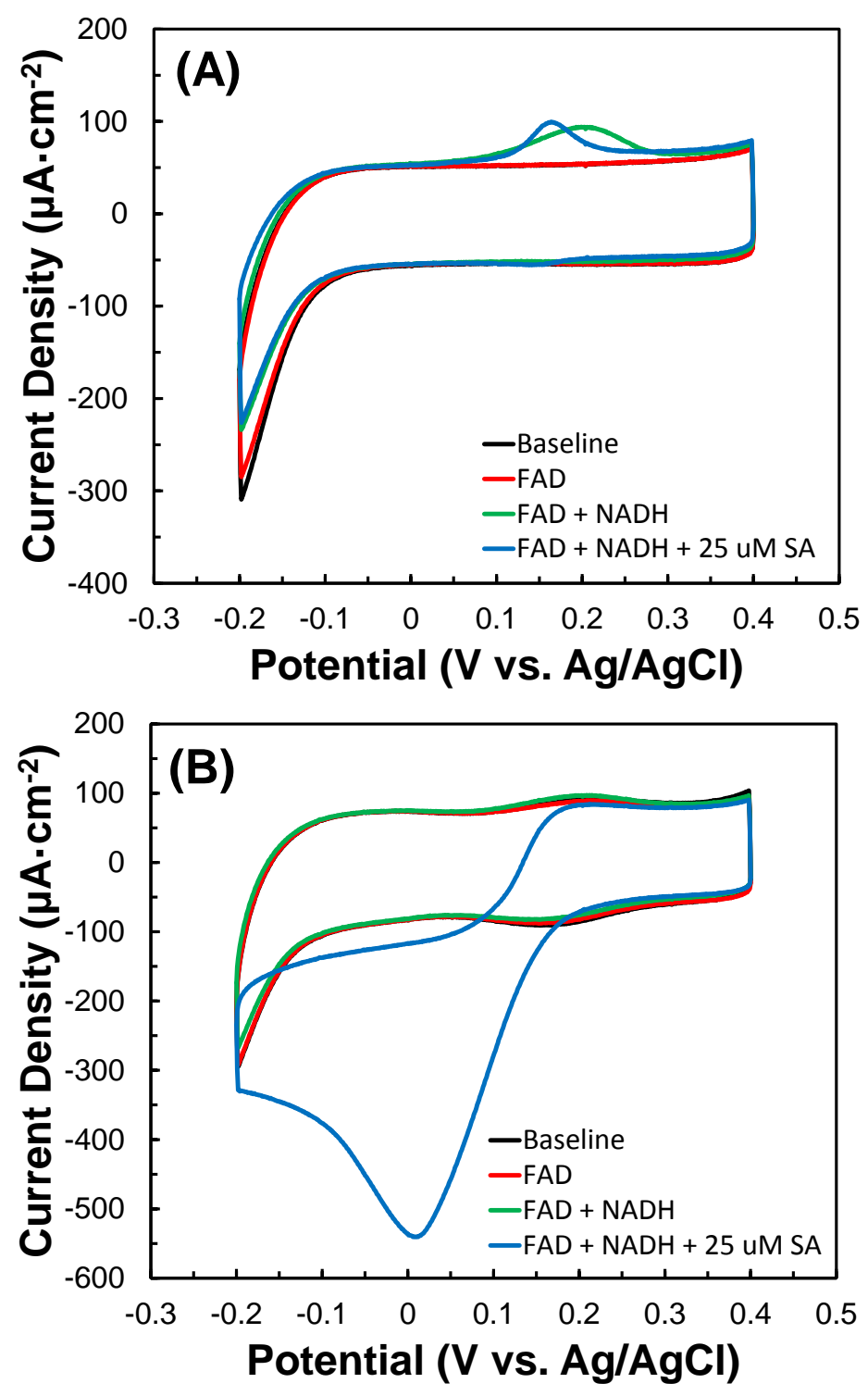

Figure 2: (A) Cyclic voltammetry after sequential addition of $100 \mu \mathrm{L}$ of $0.1 \mathrm{mM}$ FAD (Red), 50 $\mu \mathrm{L}$ of $10 \mathrm{mM} \mathrm{NADH} \mathrm{(Green)} \mathrm{and} 25 \mu \mathrm{M}$ salicylate (Blue) on salicylate hydroxylase immobilized mono-enzyme CNT electrode consisting of SH. (B) Similar set of experiments carried out on bi-enzyme CNT electrode consisting of SH and TYR. The reduction wave appearing below $0.15 \mathrm{~V}$ can be attributed to benzoquinone reduction described as step 4 in Figure 1. 

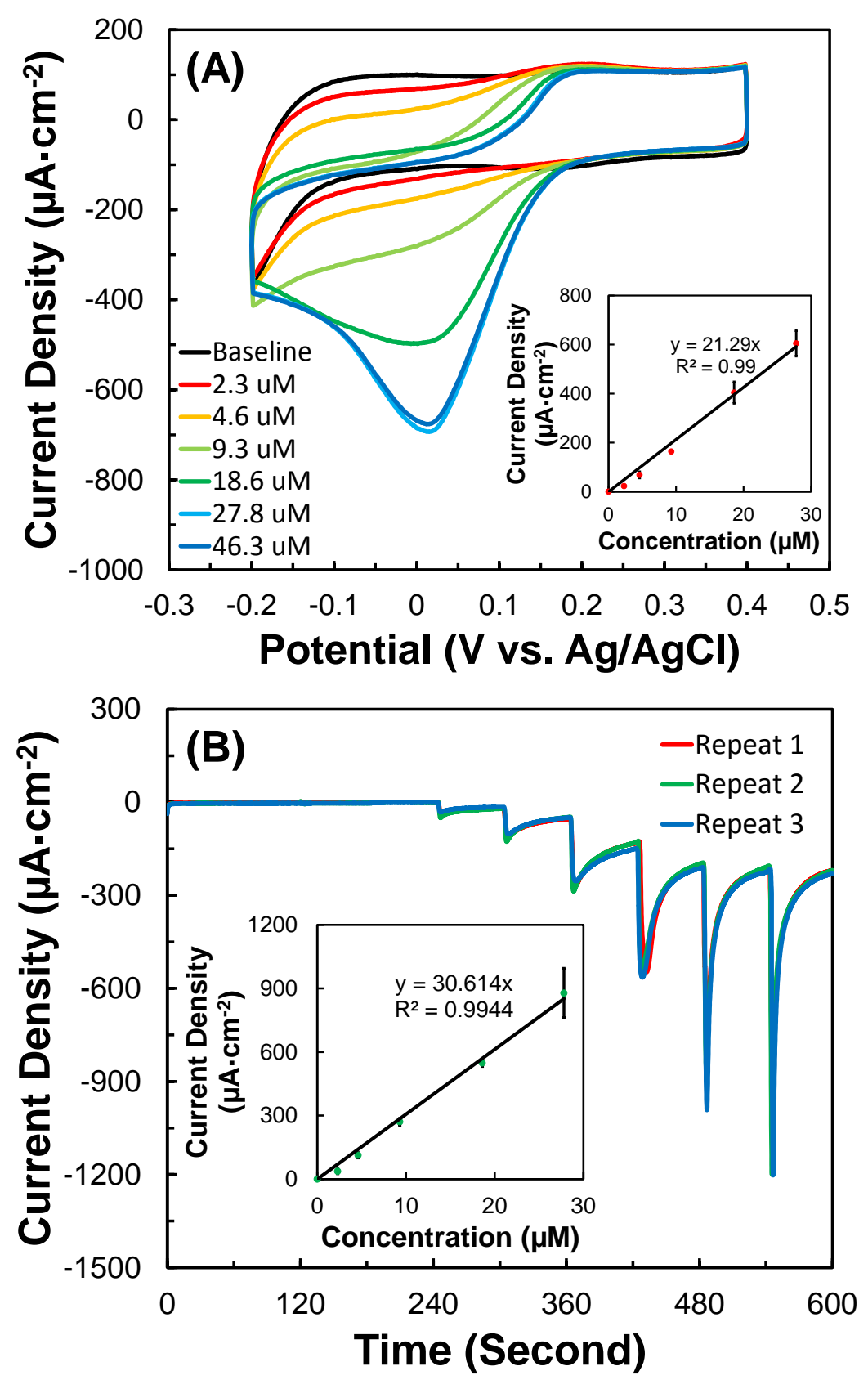

Figure 3: Cyclic voltammetry (A) and constant potential amperometry (B) responses of salicylate with presence of FAD and NADH and sensitivity, linear range and $\mathrm{R}^{2}$ value (Insert). 

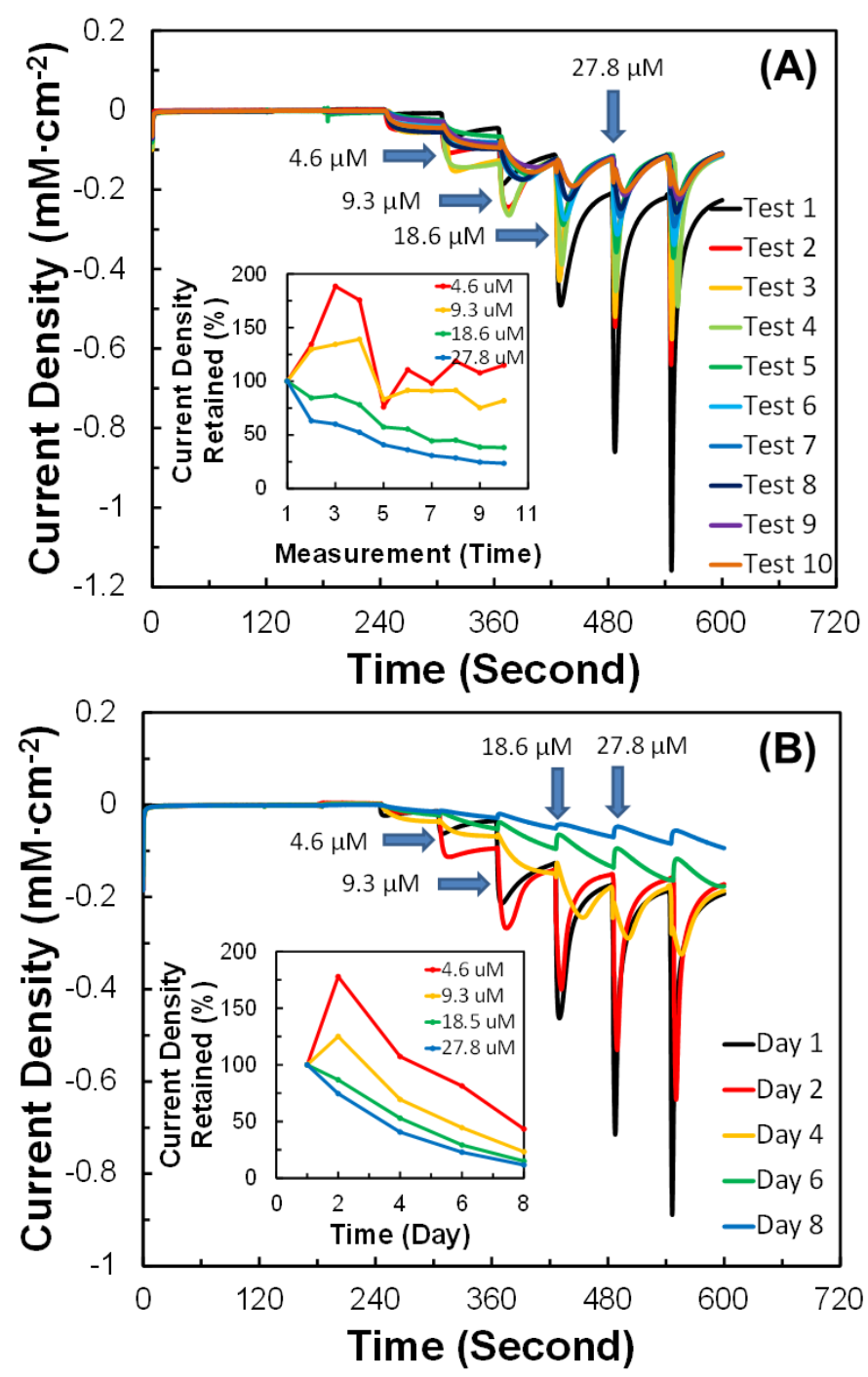

Figure 4: Reusability (A) and stability (B) of bi-enzyme biosensor for salicylate from $2.3 \mu \mathrm{M}$ to $46.3 \mu \mathrm{M}$. Current density retention over measurements in reusability (A) and time in stability (B) are displayed in insets with two low concentrations $(2.3 \mu \mathrm{M}$ and $4.6 \mu \mathrm{M})$ and high concentrations $(18.5 \mu \mathrm{M}$ and $27.8 \mu \mathrm{M})$. 

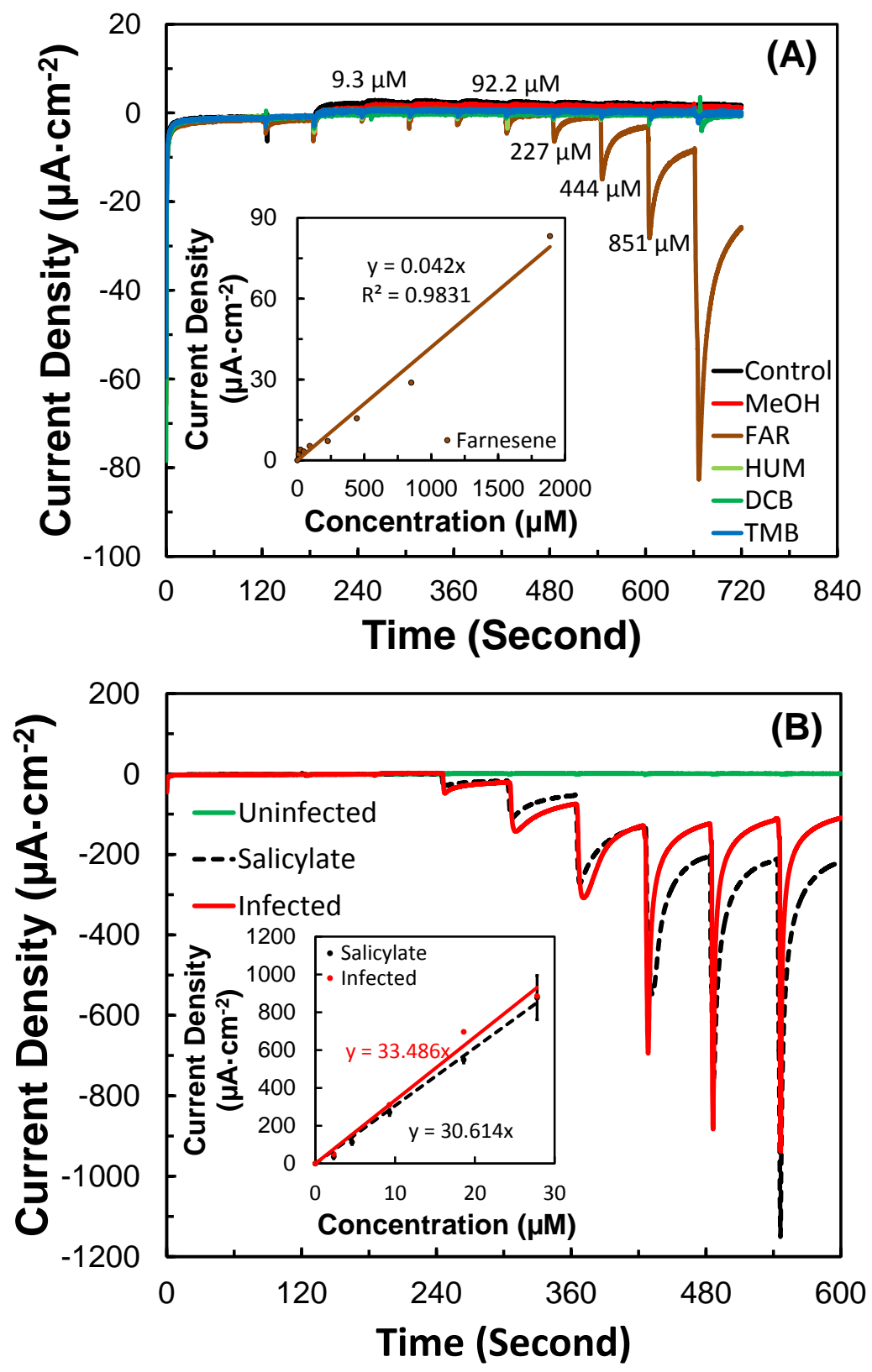

Figure 5: Constant potential amperometry responses of interference compounds - methanol $(\mathrm{MeOH})$, farnesene (FAR), humulene (HUM), dichlorobenzene (DCB), 1,2,3-trichlorobenze (TCB) and that of the control (no interfering compound) (A) and uninfected synthetic analyte, and infected synthetic analyte in simulated sample study (B). The insert graph shows the linear increase in farnesene currents with its concentration with a sensitivity of $0.042 \mu \mathrm{A} \cdot \mathrm{cm}^{-2} \cdot \mu \mathrm{M}^{-1}$ (A) and the sensitivity of the infected synthetic analyte and pure salicylate (B). 


\section{References}

Bakker, E., 2004. Electrochemical sensors. Analytical chemistry 76(12), 3285-3298.

Buttery, R., Seifert, R., Guadagni, D., Ling, L., 1969. Characterization of some volatile constituents of bell peppers. Journal of Agricultural and Food Chemistry 17(6), 1322-1327.

Cascalheira, A., Aeiyach, S., Aubard, J., Lacaze, P.-C., Abrantes, L., 2004. Electropolymerization of pyrrole on oxidizable metals: Role of salicylate ions in the anodic behavior of copper. Russian Journal of Electrochemistry 40(3), 294-298.

Dudareva, N., Negre, F., Nagegowda, D.A., Orlova, I., 2006. Plant volatiles: recent advances and future perspectives. Critical reviews in plant sciences 25(5), 417-440.

Enache, T.A., Oliveira-Brett, A.M., 2011. Phenol and para-substituted phenols electrochemical oxidation pathways. Journal of Electroanalytical Chemistry 655(1), 9-16.

Fang, Y., Ramasamy, R.P., 2015. Current and Prospective Methods for Plant Disease Detection. Biosensors 5(3), 537-561.

Fang, Y., Umasankar, Y., Ramasamy, R.P., 2014. Electrochemical detection of p-ethylguaiacol, a fungi infected fruit volatile using metal oxide nanoparticles. Analyst 139(15), 3804-3810.

Fang, Y., Umasankar, Y., Ramasamy, R.P., 2016. A novel bi-enzyme electrochemical biosensor for selective and sensitive determination of methyl salicylate. Biosensors and Bioelectronics 81, 39-45.

Godfray, H.C.J., Beddington, J.R., Crute, I.R., Haddad, L., Lawrence, D., Muir, J.F., Pretty, J., Robinson, S., Thomas, S.M., Toulmin, C., 2010. Food security: the challenge of feeding 9 billion people. science 327(5967), 812-818.

Ingram, J., 2011. A food systems approach to researching food security and its interactions with global environmental change. Food Security 3(4), 417-431.

Katagiri, M., Maeno, H., Yamamoto, S., Hayaishi, O., Kitao, T., Oae, S., 1965. Salicylate hydroxylase, a monooxygenase requiring flavin adenine dinucleotide II. The mechanism of salicylate hydroxylation to catechol. Journal of Biological Chemistry 240(8), 3414-3417.

Keinan, A., Clark, A.G., 2012. Recent explosive human population growth has resulted in an excess of rare genetic variants. science 336(6082), 740-743.

Kessler, A., Baldwin, I.T., 2001. Defensive function of herbivore-induced plant volatile emissions in nature. Science 291(5511), 2141-2144.

Kruger, N.J., 1994. The Bradford method for protein quantitation. Basic protein and peptide protocols, pp. 9-15. Springer.

Kruger, N.J., 2009. The Bradford method for protein quantitation. The protein protocols handbook, pp. 17-24. Springer.

Laothawornkitkul, J., Moore, J.P., Taylor, J.E., Possell, M., Gibson, T.D., Hewitt, C.N., Paul, N.D., 2008. Discrimination of plant volatile signatures by an electronic nose: a potential technology for plant pest and disease monitoring. Environmental science \& technology 42(22), 8433-8439.

Li, H., Wen, H., Calabrese Barton, S., 2012a. NADH Oxidation catalyzed by electropolymerized azines on carbon nanotube modified electrodes. Electroanalysis 24(2), 398-406. 
Li, H., Worley, K.E., Calabrese Barton, S., 2012b. Quantitative Analysis of Bioactive NAD+ Regenerated by NADH Electro-oxidation. ACS Catalysis 2(12), 2572-2576.

Loake, G., Grant, M., 2007. Salicylic acid in plant defence-the players and protagonists. Current opinion in plant biology 10(5), 466-472.

Mahlein, A.-K., Oerke, E.-C., Steiner, U., Dehne, H.-W., 2012. Recent advances in sensing plant diseases for precision crop protection. European Journal of Plant Pathology 133(1), 197-209.

Neto, G.d.O., Júnior, L.R., Kubota, L.T., 1999. Electrochemical biosensors for salicylate and its derivatives. Electroanalysis 11(8), 527-533.

Pawliszyn, J., 1999. Applications of solid phase microextraction. Royal Society of Chemistry.

Pichersky, E., Noel, J.P., Dudareva, N., 2006. Biosynthesis of plant volatiles: nature's diversity and ingenuity. Science 311(5762), 808-811.

Ramasamy, R.P., Luckarift, H.R., Ivnitski, D.M., Atanassov, P.B., Johnson, G.R., 2010. High electrocatalytic activity of tethered multicopper oxidase-carbon nanotube conjugates. Chemical Communications 46(33), 6045-6047.

Rassaei, L., Cui, J., Goluch, E.D., Lemay, S.G., 2012. Substrate-dependent kinetics in tyrosinase-based biosensing: amperometry vs. spectrophotometry. Analytical and bioanalytical chemistry 403(6), 15771584.

Sankaran, S., Mishra, A., Ehsani, R., Davis, C., 2010. A review of advanced techniques for detecting plant diseases. Computers and Electronics in Agriculture 72(1), 1-13.

Schmelz, E.A., Engelberth, J., Alborn, H.T., O'Donnell, P., Sammons, M., Toshima, H., Tumlinson, J.H., 2003. Simultaneous analysis of phytohormones, phytotoxins, and volatile organic compounds in plants. Proceedings of the National Academy of Sciences 100(18), 10552-10557.

Seskar, M., Shulaev, V., Raskin, I., 1998. Endogenous methyl salicylate in pathogen-inoculated tobacco plants. Plant Physiology 116(1), 387-392.

Shulaev, V., Silverman, P., Raskin, I., 1997. Airborne signalling by methyl salicylate in plant pathogen resistance.[Erratum: Apr 17, 1997, v. 386 (6626), p. 738.]. Nature.

Smil, V., 2001. Feeding the world: A challenge for the twenty-first century. MIT press.

Umasankar, Y., Ramasamy, R.P., 2013a. Catalytic Activity of Tyrosinase for Potential Biofuel Cell Application. ECS Transactions 45(11), 9-14.

Umasankar, Y., Ramasamy, R.P., 2013b. On the bio-electrocatalytic activity of tyrosinase for oxygen reduction reaction. Catalysis Science \& Technology 3(10), 2546-2549.

Umasankar, Y., Ramasamy, R.P., 2014. Enhanced Electron Transfer in Enzymatic Bioelectrodes by a Poly (vinyl alcohol) N-Methyl-4 (4'-formylstyryl) Pyridinium Methosulfate Acetal Cationic Polymer. ChemElectroChem 1(11), 1834-1839.

White-Stevens, R.H., Kamin, H., 1972. Studies of a flavoprotein, salicylate hydroxylase I. Preparation, properties, and the uncoupling of oxygen reduction from hydroxylation. Journal of Biological Chemistry 247(8), 2358-2370.

Yamamoto, S., Katagiri, M., Maeno, H., Hayaishi, O., 1965. Salicylate hydroxylase, a monooxygenase requiring flavin adenine dinucleotide I. Purification and general properties. Journal of Biological Chemistry 240(8), 3408-3413. 
You, I.-S., Murray, R., Jollie, D., Gunsalus, I., 1990. Purification and characterization of salicylate hydroxylase from Pseudomonas putida PpG7. Biochemical and biophysical research communications 169(3), 1049-1054.

You, I.S., Ghosal, D., Gunsalus, I.C., 1991. Nucleotide sequence analysis of the Pseudomonas putida PpG7 salicylate hydroxylase gene (nahG) and its 3'-flanking region. Biochemistry 30(6), 1635-1641.

Zhang, Z., Pawliszyn, J., 1993. Headspace solid-phase microextraction. Analytical chemistry 65(14), 18431852.

Zhu, J., Park, K.-C., 2005. Methyl salicylate, a soybean aphid-induced plant volatile attractive to the predator Coccinella septempunctata. Journal of chemical ecology 31(8), 1733-1746. 